\title{
Getting to Grips with Power: Action Learning for Social Change in the UK
}

\section{Jethro Pettit*}

\begin{abstract}
The transformative promises of participatory and action research can lead to a preoccupation with methods and tools, diverting attention from important questions about politics, purpose, facilitation, and the philosophical and pedagogical claims that underlie the use of these methods. Reflecting on two action learning processes with community leaders and voluntary sector workers in England, which combined a series of reflective workshops with periods of practice, this article examines the nature of the learning process, the power and position of the facilitators, and the quality of this experience as a form of participatory or action research. Looking through the lenses of the critical, reflective and experiential learning traditions that underpin participatory and action research, the article asks how these theories and practices can help to explain the process. It also asks how certain assumptions about critical and experiential learning might be problematic and - while making transformative claims - actually close down necessary reflection about power, positionality and the ethical dilemmas and imperfections that arise in all research.
\end{abstract}

\section{Introduction}

Between 2008 and 2010 the Carnegie UK Trust and the Joseph Rowntree Foundation jointly funded a programme of participatory inquiry into power and social change with community and voluntary workers in London and urban centres of West Yorkshire, England. I co-facilitated two of three action learning processes with leaders from 20 organisations, each taking part in a ninemonth sequence of workshops, practice and mentoring. Here I reflect on the quality of the learning process, on the facilitation role, and on the significance of this approach as a form of participatory or action research. I look back at what we did through the lenses of key traditions of 'critical, reflective and experiential learning' often used in participatory and action research. I ask how these theories and practices of learning might help to explain our approach, and also how their framing might be problematic - questioning my unspoken assumptions about action learning. My hope is to better articulate whether and how facilitating learning about power with community activists contributes to social change.

There are many different kinds of participatory and action research, and they are easily confused and often lumped together into a single 'alternative' by virtue of what makes them different from 'conventional' research. In this alternative, the people affected by an issue are involved in defining their concerns, their learning leads directly to changes in their practice, and their findings are also used by themselves and others to advocate change. This contrasts with conventional research in which outsiders largely define the problem, analyse it and make recommendations, which lead to changes in practice. The alternative is often portrayed as more authentic and empowering, while conventional research is seen as too abstract and theoretical, easily distorted by the power of external actors and used to impose changes from above.

I have sympathies with this view, but worry that it dangerously over-simplifies the assumed advantages and disadvantages of these contrasting approaches to research by placing too much emphasis on method. Such generalisations can obscure the normative qualities and transformative potential of experiences and practices within each of these competing streams. Conflating methods with values can hide the instrumental and manipulative uses of the alternatives, and the progressive outcomes of

IDS Bulletin Volume 43 Number 3 May 2012 (c) 2012 The Author. IDS Bulletin (c) 2012 Institute of Development Studies Published by Blackwell Publishing Ltd, 9600 Garsington Road, Oxford OX4 2DQ, UK and 350 Main Street, Malden, MA 02148, USA 
conventional research. Such framings, including those sometimes used to explain action learning, can close down reflection about the power, position and behaviour of the researcherfacilitator, and the ethical dilemmas and imperfections that arise in all research.

A better starting point for a progressive research strategy is to clarify the political and transformative intentions of the proposed process, and to reflect on the power, positionality and roles of those involved. The researcher-facilitator (if one is involved) is not neutral, but comes with certain positions, a standpoint, expectations and needs, and habitual ways of working with people and responding to social issues. The same is true for participants. Appropriate methods need to be identified, but this is no substitute for critical reflection on the power dynamics of the learning process and the actors involved. In this case, I worked for a university-based research institute and my cofacilitator for a charitable foundation. Staff from two other foundations also took part and invited their grantees to participate. Honest dialogue was needed among all participants and facilitators about our different positions and expectations. Some participants were understandably cautious and distrustful of outside academic or philanthropic agendas. Against this backdrop it would be naïve to assume that particular alternative research methods will be inherently more inclusive and progressive. It is also helpful to reflect critically on the transformative claims of the methods, the origins and theories behind them, and how they might need to be adapted or questioned in this context.

This may sound convoluted for those wanting quick advice on which action research methods to use, but methods themselves are of little value without reflecting before, during and after their use to identify contradictions and make improvements. This is the spirit of my reflection here. Did we fulfil the transformative potential of the methods and facilitation practices we used? What risks or drawbacks might be inherent in our choices and assumptions about how learning would happen? What could we have done differently to deepen the learning, including our own, and to sustain reflection and action by all? Which traditions of critical, reflective and transformative learning might help to explain our approach - and which might be problematic?
Three action learning processes were carried out, each with leaders and activists from 6-8 community and voluntary organisations working on issues of poverty, social exclusion and human rights in the United Kingdom. The participants worked with refugees and asylum seekers, racial and ethnic minorities, victims of domestic violence, adults with learning disabilities, inner city youth, young fathers, people living in lowincome housing and other groups. ${ }^{1}$ Many of the activists shared the same backgrounds as the communities and groups they worked with. They had been invited by the foundations that supported them to explore the ways in which a practical understanding of power might strengthen their abilities to contribute to social change. The learning process aimed to surface and demystify the various forms of power at work within their political, social and economic realities, and help them to affirm their own power in responding.

Our approach was inspired by similar recent initiatives in the global South and North involving non-governmental organisations (NGOs), development organisations and social movements. ${ }^{2}$ The design and methods vary across these experiences, but there is a shared idea that gaining a deeper understanding of power, and how power can be resisted, used and transformed can enhance the success of social struggles. Getting to grips with power in all its dimensions, with the help of certain concepts, frameworks and 'tools for thought' can help practitioners clarify their theories and practices of change. The assumption is that with a more critical and reflective understanding of power, social activists, organisations and communities can revisit their strategies, explore new actions, and affirm and mobilise their own power rather than dwelling only on negative experiences of power and powerlessness.

The findings and outcomes of the first round of action learning, and a discussion of how understanding power can contribute to social change, are reported by Hunjan and

Keophilavong (2010) and in a set of short videos. ${ }^{3}$ The methods used in the second two rounds are documented in a facilitators' handbook (Hunjan and Pettit 2011). Here I reflect as a co-facilitator on the second two action learning processes, and how they can be considered participatory or action research. I begin by setting the UK context and the rationale behind 'understanding power for social change' with community actors. 
Next I describe the learning process and how we expected this would contribute to change. I then explore various theories of 'critical, reflective and experiential learning' as used in action research, and assess what they offer as theoretical groundings for this approach, and how they may shape my assumptions about learning for social change.

\section{Understanding power in the UK ${ }^{\mathbf{4}}$}

Over the course of the last decade, there has been a significant push from all central governments in power in the UK to encourage the greater participation of ordinary people in decision-making processes. The policies of New Labour - which dominated during most of this period - focused not only on the relationship between citizens and national governments, but also on the roles people can play in improving their communities and public services. Initiatives and prominent themes ranged from community voice, participation, citizenship, citizen education and citizen engagement. Many of these key themes were introduced during a time of relative economic growth and stability, and new funding opportunities made it possible for civil society groups to embrace these top-down initiatives and explore new ways to engage people in democratic governance.

In the latter part of this period, there has been a significant economic decline globally and nationally, which, amongst other challenges, has had a serious impact on the funding available to organisations working with communities at the grassroots. In 2010, a Coalition government was formed by the Conservatives and Liberal Democrats, which on the one hand is implementing public expenditure cuts as a result of the recession and on the other seeking more civic voluntarism under the banner of the 'Big Society'. A government focus on empowering citizens may bring excitement and opportunity for those organisations working with communities, but this has been tempered by the challenge of budget cuts and their effects on poor and marginalised people. Some of the very organisations praised as examples of the 'Big Society' have closed their doors, found their abilities to mobilise volunteers curtailed, reduced their staffing, or become less willing to speak out about government policies (Butler 2012). Major concerns have arisen about the wellbeing of the poorest and most vulnerable sectors of society in this climate of beleaguered public and voluntary sectors. There have also been concerns that the government's discourse of 'community cohesion' shifts attention away from the patterns of injustice and prejudice experienced by certain groups. Our action learning process coincided with the economic crisis and the change in government, as the elections took place mid-way through the programme.

In this context, we set out to provide a space in which community leaders and activists could develop a more critical and practical understanding of power and how it works in British society. Power analysis in campaigning contexts is often focused on identifying and mapping the relationships between key actors and their interests, including political and civic actors and players such as businesses and the media. This analysis is used to develop advocacy tactics which often rely on professionals to influence those seen as more powerful (e.g. politicians and their advisers). While such mapping and strategising is useful, in our experience it often fails to acknowledge the sources and structures of power behind actors and their relationships, or to explore the norms, ideologies and habitual behaviours that underlie exclusion. Exposing these less visible forms of power requires awareness-raising and empowerment activities that enable people to question these underlying patterns and to articulate the change they want. By understanding power in all its dimensions, we hoped, participants would be able to envision new possibilities, affirm their own power and improve their strategies.

Power can be defined in its most basic form as the ability of people to achieve the change they want (Beetham et al. 2008). However, power is complex and a person who has power in one context or moment may be relatively powerless in another. We do not see power as static, or as being held solely by the few, but rather as something that can be found in the hands of many, and that can arise in both positive and negative forms, and that shapes the very conditions and possibilities for action. Strategies for building or transforming power can therefore work on many fronts at once - providing unexpected opportunities for those seeking change:

In reality, power is dynamic, relational and multidimensional, changing according to 
context, circumstance and interest. Its expressions and forms can range from domination and resistance to collaboration and transformation. This is good news for social justice promoters whose strategies depend upon new opportunities and openings in the practice and structures of power (Miller et al. 2006).

Our own experience confirms that without this broader understanding of power and its positive and transformative aspects, any process of analysing power could be limited and potentially disempowering, reinforcing the belief that ordinary people are powerless. A multidimensional approach can help people to better navigate the different forms of power, and to understand how social issues are shaped and changed. This process involves working with practical concepts and frameworks that shed light on different kinds of power, serving as 'tools for thought' that organisations and communities can use to make sense of the challenges they face. Power analysis is not a change strategy in itself, but a learning process that can be integrated with other change strategies related to community development, campaigning, advocacy or empowerment - expanding people's sense of what is possible.

\section{The action learning process}

The term 'action learning' is used here to describe what we did, although it differs in several respects from the tradition of Action Learning that originated in industrial and organisational settings in the UK more than 60 years ago (Revans 1983; Kramer 2007, more on this below). Over three nine-month periods we worked as facilitators ${ }^{5}$ with groups of organisations in London and West Yorkshire. The process was designed to support them to use various frameworks of power to reflect on their contexts, issues and strategies, and to identify their own sources of power and actions they might take. The London organisations worked on diverse issues, allowing them to learn and explore alliances beyond their usual circles. The West Yorkshire organisations all worked on issues related to racial justice and immigrant rights. (Note: it is also common to facilitate such action learning processes within a single organisation.)

The workshops were attended by one or two people from each organisation, each with specific issues or questions they wanted to focus on. These issues ranged from revisiting strategic plans, developing a new direction in their advocacy or services, addressing internal power or leadership issues, or starting work on a new theme. We supported the participants to explore these issues in relation to their own practice, and to do so with other stakeholders (staff, volunteers, boards, advisory groups and constituents or service users) and with other community groups, partner organisations, coalition allies, etc. Participants took part in four workshops about six to eight weeks apart. The workshops were used as a space to reflect on their context and issues, to share experiences, and to introduce and apply the various methods and frameworks for understanding power. Between each workshop, participants carried out activities in their workplaces with mentoring from one of the facilitators. An overview is provided in Box 1 .

The process was designed with certain assumptions about how it would contribute to learning. Unlike one-off training workshops, we hoped this approach would allow participants to learn over a longer period of time, and through the activities between workshops to integrate theory, reflection and practice, and to generate more experiences to reflect upon using the methods and concepts introduced in the workshops. The mentoring between workshops would support this integration and enable changes to be embedded in organisational thinking and practice beyond the lifetime of the programme. The time span would allow participants to develop relationships of trust and mutual support, and for those from different organisations, working on diverse issues but facing very similar challenges, to exchange ideas and expand their networks. By holding full-day workshops away from their day-to-day work, in a neutral environment (we hired the meeting rooms of local voluntary associations) we hoped to provide a safe space for reflection.

As facilitators, we also had expectations for our own learning about the process and methods. We were fortunate as 'outsiders' that we were under little if any pressure to generate and synthesise 'findings' for others; this was not a research project requiring any outputs beyond the participants' own learning. However, we did have expectations as facilitators, which was to document, learn from and improve the methodology, and to produce a handbook that we hoped would be useful to others (Hunjan and 
Workshop 1 - Introducing power. Building group trust and understanding. Exploring participants' positions, interests and issues, discussing the purpose and value of bringing a practical understanding of power into work and strategies. Exploring key concepts and meanings of power, grounded in personal and professional experiences, using creative methods of reflection (storytelling, drawing, conversation). Overview of action learning process, and preparing first round of action learning activities.

Action learning 1 - Observing and reflecting on power. Using simple methods of observation, participants notice and reflect on the 'forms of power' arising in their everyday work, and document these in ways that can be shared at the next workshop (e.g. keeping a journal, telling stories, drawing diagrams). Participants carry out a 'problem analysis' (e.g. Problem Tree ${ }^{6}$ with colleagues to identify the key issue they want to focus on from a power perspective.

Workshop 2 - Applying concepts and frameworks of power. Sharing observations and reflections about power and problem analyses, identifying critical issues. Reviewing concepts and frameworks of power, and discussing them in dialogue with participants' own meanings and terminology. Working in small groups using additional tools and methods (e.g. Peeling the Onion) ${ }^{7}$ to deepen analysis of the forms of power (e.g. visible, hidden, invisible power and power to, with, within) and the arenas or levels (e.g. personal, group or team, organisational, institutional, systemic).

Action learning 2 - Inquiring further into power. Exploring forms of power arising in work, pursing personal and organisational action plans in which to bring or adapt the concepts, frameworks and methods into specific activities.

Workshop 3 - Strategising with power. Mapping and presenting journeys, reflecting on common themes and challenges. Envisioning the desired change, using a metaphor or image, and identifying the forms of power for or against that change. Moving from analysis to strategy, using methods such as the Power Matrix, ${ }^{8}$ identifying strategies for responding to different forms of 'power over' and building positive forms of power.

Action learning 3 - Moving from analysis to action. Moving into strategy and taking action for challenging those forms of power that get in the way of change, and for developing alternative sources of power that can enable change.

Workshop 4 - Reflection and forward visioning. Mapping and reflecting on journeys through the action learning process, identifying lessons, insights and themes emerging from shared experiences. Reflecting forward on next steps and future directions for practical engagement with power. Evaluating the process and recommending next steps.

Pettit 2011). We also had assumptions, from our previous experiences, about the value of working with certain frameworks and concepts of power, and wanted to learn more about using them in this context. These framings inevitably gave shape and direction to the initiative - even while it responded to a strongly expressed desire among participants, fuelled by the context, to bring a more explicit power perspective into their work. But our firm belief in the value of the concepts and approach, and our hope of convincing certain academic and philanthropic audiences, inevitably affected the quality of the process as participatory or action research. This is the risk with processes (and articles) such as this, as we authors champion our methods with an evangelical zeal and don't reflect on our own framings and agendas. We found we had to be honest with the participants and ourselves, to question our preferences for using certain language and concepts, and to revisit our assumptions about the learning process. 


\section{Box 2 A selection of participants' issues for action learning}

- Leadership and alliances in a minority and ethnic community consortium.

- Repositioning women refugees and asylum seekers as empowered actors with voices.

- Challenging public perceptions and cultural norms related to female genital cutting.

- Empowering women victims of domestic violence to be aware of their rights.

- Raising consciousness of discrimination based on race and learning disabilities.

- Involving urban youth in setting the priorities of a youth organisation.

- Strengthening the voice of racial justice organisations in relation to budget cuts.

- Rethinking the strategy and direction of a migrant rights organisation.

Achieving a better balance between service delivery and policy advocacy.

\section{Participant experiences of action learning}

While we clearly had an agenda related to the learning process and the frameworks of power, the participants chose the issues they wanted to focus on, and elected to use the process in quite different ways. Some wanted to better understand and utilise their individual power as change agents, or to strengthen the power of marginalised groups within their organisations, address management or leadership issues, or enable staff to exercise more influence. Others used the process to explore ways of empowering their constituents to have more say in their organisation's priorities or in relation to local councils. Some looked at their broader organisational strategies and alliances for influencing public opinion, the media and government at the local or national level. Nearly all carried out a problem analysis of a particular issue of concern to their organisation, reflecting on their assumptions about how change happens, on their own roles, and on possible new strategies - or in some cases finding that the process affirmed the value of existing strategies (Hunjan and Keophilavong 2010; Hunjan and Pettit 2011). A summary of some of the issues they explored is shown in Box 2.

The participants' experiences were as varied as the issues they explored. Most found the multidimensional concepts and frameworks of power useful, allowing them to explore different kinds of power arising in different moments of their lives and work. Many, for example, explored the synergies and tensions between their experiences of power at the personal, family, group, organisational, institutional and societal levels, and in different kinds of spaces. These insights were helped by the 'powercube' framework (Gaventa 2006) which draws attention to how power is manifest at different 'levels' and 'spaces', and also by the notion of 'public, private and intimate' spheres of life in which one's experience of power can shift from moment to moment, particularly in relation to one's gender (VeneKlasen and Miller 2002). Participants were encouraged to observe specific moments of power in different spaces, to reflect upon and compare these stories, and also to affirm their own positive expressions of 'power to', 'power with' and 'power within'(Rowlands 1997; VeneKlasen and Miller 2002). Three examples serve to illustrate how the process unfolded for some participants.

\section{Changing organisational power}

One participant seeking to address power differences within her organisation started up an informal support group of employees who felt marginalised:

I've realised there's more to power than I thought. I used to just use the word without thinking about it. The theory has been useful to deepen it. The [support group] formed in my organisation was a space for preparation, building power, challenging decisions. We realised that power is not just about standing with banners and doing advocacy; sometimes it's quiet, 
behind the scenes, getting ready and preparing ourselves. It's not just about being in the boardrooms and committee rooms where we sit tokenistically. They don't realise that sitting around drinking coffee can be empowering.

This participant also realised that some people's perceptions of her were causing tension, and sought to address these by opening personal channels of communication. She noticed different forms of power arising at different levels, and was able to see connections between the building of personal relationships of trust, the small group solidarity work, and the eventual opening of wider organisational spaces:

I learned that settings and environments played a part in how I experienced power, and that diversity and finding common ground was a big part of building power. People's perceptions of me, I realised, was invisible power. Now I have this language to understand power, and talk to my husband about how I experience it. I want to do a workshop on power [in my organisation]. (Participant reflections in workshop)

The benefit of having 'a language to talk about power' and to break 'power' down into more specific terms was echoed by many participants. But it was often pointed out, importantly, that the best definitions may not use the same language, terminology, or even concepts of the facilitators. Early on we realised that we needed to hold back on imposing our own terms and frameworks, to listen more, and to respect the many ways in which participants were already analysing and engaging with power issues, using ideas and words that made sense to them. It was not easy to 'let go', as we were also convinced that we had something genuinely useful to offer. But over time we became less concerned about using terminology from the frameworks, and more comfortable as the participants improvised and use their own words.

\section{Emancipatory learning and group empowerment}

Many found that even where the frameworks did help to sharpen their analysis and give them a 'language', they still had to 'translate' this into meaningful words in their work with peers and communities, and to find more relevant metaphors and examples. A participant working with African-Caribbean adults with learning disabilities found our abstract words disempowering, and that facilitating a process of creating a meaningful language with his community group was vital and empowering in itself:

'Nothing about us without us' is the slogan of the group of people I work with. In this process there has been a challenge for them in using abstract concepts and analysis: it's better if I am an intermediary and reinterpret for them. It's useful to have a language of social justice and human rights, and help them to develop and use this language. For example, 'mental slavery', and how heritage and identity affects people related to both their disability and race.

This participant found that the challenge of translation and learning was not limited to words and language, but also required the use of images, metaphors and examples. In the workshops we used cartoons, drawing, diagrams and role plays to visualise or enact different experiences of power. This participant was also accustomed to using imagery and metaphor in his approach to raising awareness about the historical causes of racism and discrimination based on disability, and adapted some of the materials we used:

Gaining knowledge is key, and using images works best: exhibitions, photos, film clips. They enjoyed them. The challenge is how to organise it and apply it: that's where this [action learning] group has been useful. Simple tools like the Problem Tree... It helps to have ideas that make it simpler, relating to themselves first, then seeing how they can pass it on to others. We also look at cases, such as the US civil rights case of mixed marriages, or making connections between slavery (restraint, chains, and manacles) and disability (straightjackets).

In one workshop the participants developed their own metaphor of the positive and negative meanings of power using the image of a butterfly - an idea which many were quickly able to identify with and refer to in the dialogue that followed (see Figure 1).

The participant working with adults with learning difficulties also affirmed the value of working from personal experiences of power, through storytelling, rather than applying abstract concepts to the experiences of others. Again, links were revealed between the personal, the group and the wider system: 


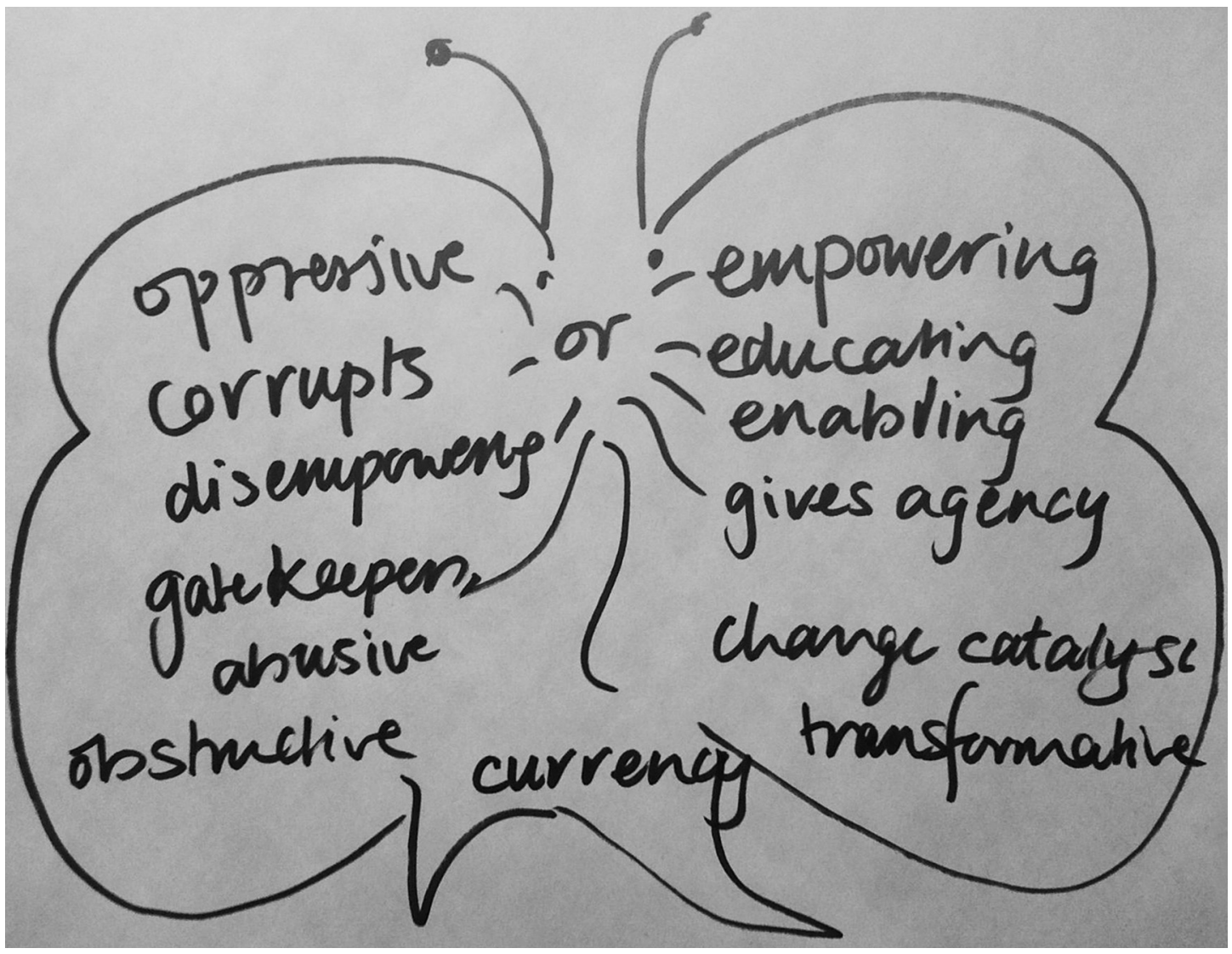

[They're] digesting experience, not at an abstract level but relating to their own experience. And you need to understand it well enough yourself to be able to communicate it to others. It's also about creating the space for this to happen. Coming here has been useful in giving me ideas that I can take back to the group. It takes time. (Participant reflections in workshop)

\section{Empowering women refugees and asylum seekers}

Several participants were concerned with how to ensure that the members or users of their services had more power and voice within their organisation, and in relation to other actors such as the media or local government. For many this concern came from experiences of members (including themselves) being used or manipulated by more powerful actors claiming to speak on their behalf or act in their interests. One participant, working with African women refugees, found that the power frameworks provided new avenues for navigating and contesting these power relations:
I've questioned what's going on around me from an early age. My organisation is sometimes seen as 'me' and powerful agencies use me to gain access to the women's group. Donor agencies define the problem and what they want to give. But we need to ask ourselves: why are we being invited into this space? We didn't ask this before.

But like others, this participant found that there was a need to adapt and translate the power concepts introduced in the workshop when engaging with the community:

The power terms and frameworks are very complex, sometimes too complex. I realised we need to avoid the terms, and just put them into practice.

As an example of 'just putting the concepts into practice' this participant reflected on a change in attitude among the women about whether and when to enter 'invited spaces' such as local government consultations, rather than blindly accepting all requests: 
Box 3 Participant feedback on action learning

Taking part in this project helped me to understand that I have got power, and that I should be comfortable with this, and use this to both influence on behalf of others and also open doors so that they can exercise power too.*

I had expected it [the project] to be about understanding power as something oppressive. Instead it was a much wider scope, understanding power in terms of enabling in order to move things on.*

We've realised we've got the power within ourselves to change the situation. Awareness of our context is important, understanding the situation: what we have to do is get what we need within it.**

I was criticised for being too confrontational: people said why kill with poison when you can kill with sugar? For example, in getting capital improvement funds from local authorities for renovation of community centres we discovered the strength of coming together under an umbrella organisation... Before it was divide and rule. Unity has been a real benefit things we apply for get approved. Unity is vital for power.**

Everyone wants to do work about us, not with us, like we are school children. The project made me realise this was all about power and we needed to make ourselves more visible.*

I hadn't thought about how to use the power of the community before. It made me think, 'Let's work together'.*

You can't empower people - it's more about getting out of people's way so that they can exercise their own power.*

* Participant feedback in final individual interview.

** Participant feedback in final workshop.

Now when they ask us to come with our bodies or our heads we stop and think why, and what can we get out of it, even if it is just food or funds. They have their own strategies so we have to analyse: what do we get out of this?... Are we being used, are we being abused, or is it genuine participation? Now we're saying, 'Give us resources, don't just ask us to be present'... But we also realised that just taking food was not empowering - we want to have influence and power. So now we're deciding what spaces we want to have influence in.

(Participant reflections in final workshop)

\section{Participant feedback}

A major current of feedback, at the end of all three learning processes, was a renewed sense of the importance of personal and collective power - and with it an appreciation of power as not just a negative force of control or domination, but (as in the butterfly) as a positive and necessary force for change (see Box 3).
Clearly the action learning process contributed to profound insights for many of the participants. But it's important to look behind this feedback, and to question our assumptions about how the process worked with a more critical eye. I now ask how the traditions of participatory and action research - and specifically the methods of critical, reflective and experiential learning used within them - might frame our approach and explain its strengths and limitations.

\section{Critical, reflective and experiential learning}

Participatory and action research have many principles in common with traditions of adult learning - what I call here the traditions of critical, reflective and experiential learning. This is not singular methodology, but includes a range of approaches that view learning as a primary vehicle for personal, organisational and social change. These approaches overlap in practice and are easily confused, using much the same language, but there are important differences 
worth noting in terms of their origins, aims and philosophical groundings (Finger and Asún 2001). I compare these learning traditions to see how they might explain or challenge my assumptions about this learning process.

\subsection{Action learning and experiential learning}

Our approach shares the name and certain features with the 'Action Learning' methods first used in the 1940s by Reg Revans to help UK coal industry managers solve their production problems (Revans 1983; Kramer 2007). This original definition of action learning recognises that groups of practitioners facing similar challenges can be trusted to reflect on their experience, ask good questions and develop practical solutions often better than outside experts can, and even without the help of facilitators. An important facet of the process is the ability to question one's underlying assumptions:

The basic principle of action learning is that only those who have learned how to change their own mindsets - their own taken-forgranted assumptions, beliefs and attitudes can change the taken-for-granted assumptions, beliefs, and attitudes embedded in the culture of an organization. This requires deep exploration of emotional experience at both the individual and group levels. 'Those unable to change themselves,' wrote Revans (1983: 55), 'cannot change what goes on around them' (Kramer 2007: 217).

There have since been many versions of action learning, mostly used in organisational settings to improve effectiveness or performance. While our process shares much in common with this kind of action learning, there are also differences. In many industrial settings participants are not usually encouraged to ask deeper questions that might challenge organisational values, purposes, or hierarchies - rather it is hoped that they will correct errors and become more effective within certain given parameters. In contrast we supported participants to ask what we hoped were quite probing questions about their issues, contexts and themselves as actors - and saw this critical analysis and reflection as a change strategy in its own right, in addition to any actions that might follow. I would agree that practitioners are often the best problem solvers when given more control over their work, but would add that requires paying attention to power, and going beyond taking corrective actions within a given structure.

Ideas about how practitioners in organisations can be involved in deeper learning and problemsolving have been further articulated by Chris Argyris and Donald Schön (Argyris and Schön 1974, 1978; Argyris 1981; Schön 1983). Reflection on experience, they argue, needs to go beyond 'single loop learning' where we notice and correct errors within the existing rules, to 'double loop learning' where we re-evaluate the norms and assumptions that frame our actions (Argyris and Schön 1974), as in Action Learning. Our behaviour is guided by mental models that we are usually unaware of, creating gaps between our 'espoused theory' (what we say we are doing) and our 'theory in use' (what we actually do) (Argyris 1981). Double loop learning is meant to narrow this gap through 'reflection in action' (Argyris and Schön 1978: 18). Where done collectively, as in a workplace, double loop learning can 'resolve incompatible organizational norms by setting new priorities and weightings of norms, or by restructuring the norms themselves together with associated strategies and assumptions' (Argyris and Schön 1974: 28).

This approach seems closer to what we were attempting. Yet while I recognise these kinds of reflective loops as implicit in our process, I have doubts about the linear pathways of learning and action that they imply. The cyclical model of how learners shift their framings and behaviour has been widely advanced in the field of education by David Kolb - whose 'learning cycle' moves through four stages of action and reflection: concrete experience, reflective observation, abstract conceptualisation, and pragmatic action (Kolb 1984). Similar loops and cycles appear in many methods of action learning and action research, taking as given that we can best make sense of things by 'cycling' between our lived experience or actions and various modes of reflection and analysis. Action-reflection at its most basic level can be seen as the process of 'learning by doing' in the course of human development.

I can recognise the cyclical qualities of our action learning process in the ideas of Argyris, Schön and Kolb, but they somehow do not explain the full picture. Our design did build in moments of reflection, dialogue, analysis and action: 
participants used the workshops and mentoring to reflect on their experiences in-between sessions, and to question the norms and behaviour underlying their practice. We did aim to question internalised framings and assumptions, for example about the role of community and voluntary organisations in the context of the 'Big Society' and 'community cohesion' discourses. Many participants ended up asking quite critical questions of themselves and their organisations, for example:

The fight has gone out of our sector; they've been colluded by the language of cohesion. Words are powerful, and we need to disrupt this language e.g. 'Big Society' = B.S.

(Participant reflection in workshop)

The community cohesion strategy is so clever: gatekeepers want to protect their jobs. They want us to forget that we are excluded and think about cohesion. I take a person-centred approach, not a standardised, one-size-fits-all. At a personal level, it's important to build personal relationships, and connect with people who speak the same language. We need to work across the gender/race divide, and not reproduce inequalities. We've realised we've got the power within ourselves to change the situation.

(Participant reflection in workshop)

Reaching this level of reflection was certainly helped by the frameworks of power, in what might be seen as the abstract conceptual (Kolb) or double loop (Argyris and Schön) stage, opening up new perspectives on familiar issues and patterns. Participants also imagined possibilities for action with a greater sense of personal and collective power, in what could be described as the pragmatic, or action, stage of the cycle. But there were also qualities that didn't conform to this model. We never set out to facilitate cycles in neat stages. Our process was layered, emergent and iterative, with participants making sense of their experiences in different ways at different times. This was not always comfortable, and participants often expressed frustrations, whether about the use of too much theory, too many tools or overly abstract language. They also explored the feelings and emotions arising from their reflections on power, and expressed these through drawings, diagrams, journals, and personal conversations, not only through abstract analysis. I can't easily identify conceptual or double loop moments as the main markers of change in participants' thinking or action.

In this light Kolb's cycle in particular seems overly linear and logical, placing abstract thinking at the privileged apex of the learning process, and implying that what we know through our feelings and senses must be observed, analysed and rationalised to become useful, and that improved action always flows from abstract analysis. Similarly, Argyris and Schön's double loop learning can be understood as prescribing a rather linear, managed process one of many criticisms that have been made of the 'managed' or facilitated uses of learning cycles (see Taylor 1998; Fenwick 2001) and later conceded by some learning cycle advocates, for example:

Schön, in his later work on reflection-in-action draws on his pragmatist heritage (and especially the work of Dewey) and presents the making of theory-in-action and the expression of professional artistry in a far less linear fashion. Rather than there being phases, we could argue that intervention of this kind involves a number of elements or dimensions working at once (Smith 2001).

To better understand how the learning processes worked I could trace the origins of these learning cycles to the early twentieth century pragmatist philosophy of John Dewey (1997/1938). Experiential education for Dewey was not so much a method to be managed (as it later became for many of his followers), but an explanation of the process of human development and the shaping of communitarian and democratic values (Finger and Asún 2001: 36). Dewey believed that we develop in a 'learning circle' in which our lived experiences undergo a process of 'habituation', the formation of 'habits' and 'actions' which we perform on the basis of these habits, leading to further experiences that we learn from (Finger and Asún 2001: 36). Dewey is thus considered 'the founding father of experiential learning...' (Finger and Asún 2001: 36) and has been the main inspiration for later albeit more linear and managed - models of action and reflection.

Our learning process may rest more easily with the principles and philosophy of Dewey than with some of the managed learning techniques that 
his philosophy later inspired. The challenge of learning about invisible, internalised and socialised forms of power, for example, can be explained by his idea that 'habituation' is not merely 'a fixed way of doing things' or a gaining a conceptual grasp of what is true; rather, habituation 'covers the formation of attitudes, attitudes that are emotional and intellectual; it covers our basic sensitivities and ways of meeting and responding to all the conditions which we might meet in living' (Dewey 1997/1938: 87-8). Dewey's thinking about how we learn and develop as human beings inspired a revolutionary shift in some American schools away from didactic instruction and toward more experiential, multisensory and creative approaches to teaching. ${ }^{9}$ But Dewey's Progressive Education movement was not about managing explicit cycles of learning, it was about facilitating a multi-dimensional and learner-centred process of human development - recognising the need to cultivate what have more recently been called our 'multiple intelligences' (Gardner 2006).

If power is a multi-dimensional experience, socialised and habituated as described by the frameworks of power, then the way we learn about it needs to tap into our multiple ways of knowing. In this learning process the experiential learning cycles were present, but not over-orchestrated or managed. We aimed to create opportunities for various kinds of reflection on experience, using all the senses and feelings, including dialogue, imagery and metaphor, and encouraging this in a safe group environment as well as through individual reflection. We did introduce critical analysis using concepts and frameworks, but in such a way (we hoped) that they did not superimpose abstract meanings on the participants' experience and their own creative intelligence. However, it is clear that efforts to stimulate and manage reflection on experience will be fraught with contradictions that need to be considered (see Fenwick 2001).

One misgiving about the pragmatist tradition of experiential learning is that it doesn't explicitly raise questions about power - especially the kinds of power understood as hegemonic knowledge and internalised social norms (e.g. Gaventa and Cornwall 2001). Dewey's progressive and communitarian idealism has been criticised for taking the 'progressivism' of the modernisation paradigm as given rather than questioning it (Finger and Asún 2001). Similarly, double loop learning as used in many management contexts has been criticised for not attending to politics and power in organisations (Easterby-Smith and Araujo 1999:13, cited in Smith 2001): again, it is about improving performance and self-management within existing parameters (Fenwick 2001). Given that the purpose of our learning process was to help participants expose and question dominant belief systems that uphold power relations and marginalise people, I could turn to more emancipatory theories of learning.

\subsection{Critical pedagogy}

A major influence on both participatory action research and adult education has been the literacy methods developed by the Brazilian educator Paulo Freire (Finger and Asún 2001: 77), inspiring the field of 'critical pedagogy'. Freire's 'pedagogy of the oppressed' (1970) enables people living in poverty and exclusion to see their situation with fresh eyes - and to recognise it as the outcome of unjust and man-made structures that can be questioned, rather than as something to be passively accepted as the natural order of things. This 'conscientisation' process aims to break the 'culture of silence' that comes with the widespread internalisation of certain beliefs exposing and challenging the socially constructed truths that perpetuate injustice (Freire 1970).

Much of the inspiration behind critical pedagogy comes from Marx and Gramsci, via the critical theory of the Frankfurt School and especially Habermas (Finger and Asún 2001: 78). Critical theory observes that not only do we internalise ideologies, but our very way of thinking about ideology is conditioned by prevailing norms of rationality - leading Habermas to distinguish between the 'instrumental rationality' that upholds capitalist society, and the 'critical rationality' needed to be able to see through it and to propose alternatives (Habermas 1987). The idea that rationality itself can deceive is profound: critical theorists were worried not only about the alienating effects of capitalism, but the alarming distortion of Enlightenment reason in the rise of European fascism, and so they encouraged a more critical form of rational discourse (Finger and Asún 2001: 78). Habermas proposed the need to create ideal speech situations' where people could discuss social realities without these distortions, leading to 
'communicative action' (Habermas 1987). Freire builds on this idea, asking learners to question not only values and structures, but their own deeply conditioned ways of thinking about them, and to reaffirm their own dignity. Without such critical consciousness, even with revolutionary change, the oppressive order will simply reassert itself through imitation of the powerful.

In a sense our action learning process did try to provide safe spaces or 'ideal speech situations' where participants could think critically and question the ideologies that reproduce social order, but whether we fulfilled the transformative promise of critical pedagogy is hard to say. The power frameworks were revealing to participants when used creatively and iteratively with their experience - pointing for example to the 'invisible power' of knowledge, attitudes and beliefs and the 'power within' of dignity and self-respect. Many participants did report that the concepts and frameworks helped them to question truths and assumptions about how power works and about their own disempowerment. Methods that encourage us to question our paradigms and framings clearly play a role, and this principle from critical pedagogy has given rise to the hugely influential field of transformative learning (see Mezirow 1991, 2000) which blends Dewey's pragmatism with Freire and Habermas' critical theory (Finger and Asún 2001).

But how to facilitate this process of transformation is not so straightforward, and again seems to involve much more than an abstract-conceptual reframing of assumptions. In our action learning process the moments of sense-making seemed to rely much more on there being relationships of trust and good communication, creating and holding safe spaces for conversation, and allowing time to face contradictions and express feelings. The learning was mutual and collective rather than individual. We tried to bring a good deal of compassion, creativity and dialogue to the process, and invited people to introduce their own framings and language, in addition to bringing in our concepts. The conditions were rarely 'ideal' and the disparities of positions, backgrounds, genders and values in the groups (including mine) undoubtedly constrained what could be expressed about power. More time and less pressure on everyone would also have allowed us to go much further. But the process of building trust and relationships contributed as much, if not more, than the concepts or analytical stages of learning. Critical pedagogy and transformative learning do have much to say about the need for this kind of attention to process, safety, trust and dialogue, but these process issues sometimes get lost in the focus on critique of ideology and assumptions, and can also miss out on naming the more intimate and personal dimensions of power, for example the norms of power that reproduce gender inequalities. For this reason I would see what feminist approaches to learning might offer.

\subsection{Feminist pedagogy}

Feminist educators and action researchers draw on many principles of critical pedagogy, but encourage participants to question the social construction of gender norms through individual and group reflection - a process that necessarily includes the personal and interpersonal dimension (e.g. Brydon-Miller et al. 2003). Feminist pedagogy goes beyond critical pedagogy by encouraging learners to explore their own lives and narratives, and the way gender norms are reproduced in the intimate and relational spheres of their lives, rather than only analysing visible or ideological structures of power 'out there' (e.g. Personal Narratives Group 1989). This connecting of the personal to the political was present in our action learning process, where we encouraged the use of narratives, stories, pictures and conversations to give legitimacy to ways of knowing that allow the personal and political to be explored together. A key inspiration for this has been the methods we adapted from VeneKlasen and Miller's New Weave of Power, People and Politics (2002), a blend of Freirian and feminist adult education methods.

We perhaps did not have sufficient space or trust for deeper exploration of gendered power norms, partly due to the diversity and mixed gender of the groups, but we did explore intimate and personal dimensions of power through tools such as the Power Flower ${ }^{10}$ (VeneKlasen and Miller 2002) and Peeling the Onion (Hunjan and Pettit 2011), and some participants took inquiry into this further than others. Probably the principle we borrowed most from feminist pedagogy, within the limits of our process, was that of the need to explore power at the intimate and personal levels - and to connect these with structures of power in society, and their transformation. 


\section{Conclusion}

The action learning process we facilitated clearly draws much inspiration from diverse traditions of critical, reflective and experiential learning and these each help to explain and support different aspects of the methodology and the participants' feedback. The original principles of Action Learning, which trusts practitioners to solve their problems, can be taken further with 'double loop' questioning of values and assumptions; but there are risks in becoming too directive with linear 'cycles' of learning. Experiential learning cycles can be overconceptual in emphasis, and miss the iterative, creative and embodied dimensions of learning with our 'multiple intelligences'; they can be too individualistic and miss the learning that comes in safe, collective spaces; and they do not always account for power or question given hierarchies and structures. Critical pedagogy invites a deeper critique of ideology and structure, but retains a conceptual and analytical weighting that can crowd out other kinds of sense-making. Feminist pedagogy extends the critique to gender and patriarchy, uses narrative to invite an exploration of the intimate, and connects the personal to the political. Each of these framings is in itself a form of power, in that it builds a vivid, internalised construct about how we

\section{Notes}

* The author is grateful to Raji Hunjan who co-designed and co-facilitated all of the action learning processes described in this article, and provided invaluable insights and comments on various drafts. I am grateful to the Carnegie UK Trust, the Joseph Rowntree Foundation, the Trust for London (formerly City Parochial Foundation) and the Joseph Rowntree Charitable Trust for their active participation in supporting this work on understanding power, by contributing funds, collaborating with the facilitators to develop and share the learning, and encouraging grant recipients to try out different approaches to power analysis.

1 These organisations were Shpresa, Migrant and Refugee Communities Forum, Naz Project London, Eaves Housing, Spare Tyre Theatre Company, Praxis, Disability Action Islington, Fitzrovia Youth Project, Women and Girls Network, Forward, Iranian and Kurdish Women's Organisation, African Women's Support Project, Roots, Huddersfield learn, and how our learning contributes to social change.

Reflecting on our action learning process through these lenses, I find that they each provide certain useful, yet still quite incomplete, groundings for a theory of change. These framings of critical, reflective and experiential learning probably shaped our design and facilitation more than we might think. For all their differences, these traditions are all rooted in a common paradigm of liberal and critical Enlightenment thought which has its own implicit models of cognition and learning. Our entire social and cultural context, including our outlook as both learners and facilitators, is shaped to some degree by this larger philosophy, and so it is natural to find resonance and success in using and explaining our approach with these traditions. But there were qualities of the learning process that evade these models of learning, and call into question the rational-objectivist paradigm and mind-body dualism behind them. These were the qualities of relationships, of communication in all its dimensions (Ortiz Aragón, this IDS Bulletin), of intimate and personal inquiry, and of creative, embodied and emotional expression that cannot be easily reduced to linear cycles of action, reflection and reframing.

Pakistani Muslim Association, JUST West Yorkshire, Clover Leaf Advocacy, Refugee Forum Leeds. The author is grateful to the participating organisations for trusting us with the process of strengthening their own work and also advising us on how power analysis could help many more in the future.

2 Many individuals and organisations have contributed to these processes and to the innovative methods of power analysis used, including John Gaventa at IDS, Jo Rowlands at Oxfam GB, Lisa VeneKlasen and Valerie Miller at Just Associates and Irene Guijt at Learning by Design and many others. For an overview and access to documents related to these initiatives, see www.powercube.net. A major inspiration for supporting power analysis with social movements and feminist activists around the world has been Just Associates: www.justassociates.org. The action learning processes described here by the author were inspired by two Learning Trajectories designed and facilitated by Irene Guijt and Jethro Pettit in the Netherlands in 
2007 and 2009. Further ideas and innovations came from Soumountha Keophilavong, Charlotte Flowers, Maro Pantazidou, Maureen Grant and the author, among others.

3 This report (Hunjan and Keophilavong 2010) is supplemented by a series of short video case studies illustrating how some of the organisations involved in the project benefited from the experience: www.carnegieuktrust.org.uk/2005-2010programme/democracy/.

4 This section is adapted from Hunjan and Pettit (2011).

5 Charlotte Flower facilitated the first action learning process with support from Raji Hunjan and Soumountha Keophilavong. Raji Hunjan and I facilitated the second two action learning processes with support from Maro Pantazidou in London and Maureen Grant in West Yorkshire.

6 A Problem Tree is a graphic method used to analyse the 'roots and fruits' of a problem or issue, usually in the form of a diagram of a tree onto which participants draw or write these dimensions of the problem on the roots and branches (VeneKlasen and Miller 2002; Hunjan and Pettit 2011).

7 Peeling the Onion is a visual mapping exercise devised for this action learning process, in which participants analyse the forms of power that are working for or against

\section{References}

Argyris, C. (1981) Reasoning, Learning and Action, San Francisco: Jossey-Bass

Argyris, C. and Schön, D. (1978) Organizational Learning: A Theory of Action Perspective, Reading MA: Addison-Wesley

Argyris, C. and Schön, D. (1974) Theory in Practice: Increasing Organisational Effectiveness, San Francisco: Jossey-Bass

Beetham, D.; Blick, A.; Margetts, H. and Weir, S. (2008) Power and Participation in Modern Britain: A Literature Review for the Carnegie UK Democracy and Civil Society Programme, London: Democratic Audit

Brydon-Miller, M.; Maguire, P. and McIntyre, A. (eds) (2003) Traveling Companions: Feminism, Teaching, and Action Research, Westport CT: Praeger

Butler, P. (2012) 'Charities Scared to Speak Out Amid Cuts, says Report', London: The Guardian

Dewey, J. (1997/1938) Experience and Education, New York: Touchstone a desired change at all levels, represented in concentric circles radiating outward - from the personal or individual, to the group or team, to the organisational or institutional, to the social or systemic.

8 The Power Matrix is a tool for listing examples of visible, hidden and invisible forms of power behind a problem or issue, and identifying appropriate strategies that respond to these examples of power, and their interconnections (VeneKlasen and Miller 2002).

9 As a child I attended progressive schools that had been inspired by Dewey's Progressive Education movement, and experienced the learning process as one with multiple dimensions, including creativity and embodiment, the learning of practical skills and cooperative values, but never one of explicitly managed cycles.

10 The Power Flower is a visual tool in the form of a flower with two layers of concentric petals: each petal in the outer layer represents a form of identity of the dominant or powerful actors in society, such as their gender, race, age, religion, language, sexuality, education, etc. The inner petals represent the same identity characteristics for the individual or group doing the analysis. Participants discuss the ways in which their different identities conform or not with those that prevail in society.

Easterby-Smith, M. and Araujo, L. (1999)

'Current Debates and Opportunities' in M. Easterby-Smith, L. Araujo and J. Burgoyne, Organisational Learning and the Learning Organisation, London: Sage

Fenwick, T.J. (2001) Experiential Learning: A Theoretical Critique from Five Perspectives, Information Series, Columbus OH: ERIC Clearinghouse on Adult, Career and Vocational Education

Finger, M. and Asún, J.M. (2001) Adult Education at the Crossroads: Learning our Way Out, London: Zed Books and National Institute of Adult Continuing Education (NIACE)

Freire, P. (1970) Pedagogy of the Oppressed, New York: Herder \& Herder

Gardner, H. (2006) Multiple Intelligences: New Horizons, New York: Basic Books

Gaventa, J. (2006) 'Finding the Spaces for Change: A Power Analysis', IDS Bulletin 37.5, Brighton: IDS

Gaventa, J. and Cornwall, A. (2001) 'Power and Knowledge', in P. Reason and H. Bradbury, 
The Sage Handbook of Action Research: Participative Inquiry and Practice, London: Sage: 70-80

Habermas, J. (1987) The Theory of Communicative Action, Volume Two: Lifeworld and System: A Critique of Functionalist Reason, Boston: Beacon Press

Hunjan, R. and Keophilavong, S. (2010) Power and Making Change Happen, Dunfermline: Carnegie UK Trust, Democracy and Civil Society Programme

Hunjan, R. and Pettit, J. (2011) Power: A Practical Guide for Facilitating Social Change, Dunfermline: Carnegie UK Trust, Democracy and Civil Society Programme

Kolb, D. (1984) Experiential Learning: Experience as the Source of Learning and Development, Englewood Cliffs NJ: Prentiss Hall

Kramer, R. (2007) 'How Might Action Learning be used to Develop the Emotional Intelligence and Leadership Capacity of Public Administrators?', Journal of Public Affairs Education 13.2: 205-42

Mezirow, J. (ed.) (2000) Learning as Transformation: Critical Perspectives on a Theory in Progress, San Francisco: Jossey-Bass

Mezirow, J. (1991) Fostering Critical Reflection in Adulthood: A Guide to Transformative and Emancipatory Learning, San Francisco: Jossey-Bass Miller, V.; VeneKlassen, L.; Reilly, M. and Clark, C. (2006) Making Change Happen: Power-Concepts for Revisioning Power for Justice, Equality and Peace, Washington DC: Just Associates

Personal Narratives Group (1989) Interpreting Women's Lives: Feminist Theory and Personal Alternatives, Bloomington IN: Indiana University Press

Revans, R.W. (1983) The ABC of Action Learning, Bromley: Chertwell-Bratt

Rowlands, J. (1997) Questioning Empowerment: Working with Women in Honduras, Oxford: Oxfam Publications

Schön, D. (1983) The Reflective Practitioner, New York: Basic Books

Smith, M.K. (2001, updated September 2009)

'Chris Argyris: Theories of Action, Double-loop Learning and Organizational Learning', The Encyclopedia of Informal Education, www.infed.org/ thinkers/argyris.htm (accessed July 2012)

Taylor, E.W. (1998) The Theory and Practice of Transformative Learning: A Critical Review, Columbus OH: ERIC Clearinghouse on Adult, Career and Vocational Education, College of Education, Ohio State University

VeneKlasen, L. and Miller, V. (2002) A New Weave of Power, People and Politics: The Action Guide for Advocacy and Citizen Participation, Oklahoma City: World Neighbors 